\title{
Papers
}

\section{Randomised controlled trial of primary school based intervention to reduce risk factors for obesity}

\author{
Pinki Sahota, Mary C J Rudolf, Rachael Dixey, Andrew J Hill, Julian H Barth, Janet Cade
}

\begin{abstract}
Objective To assess if a school based intervention was effective in reducing risk factors for obesity. Design Group randomised controlled trial. Setting 10 primary schools in Leeds. Participants 634 children aged 7-11 years. Intervention Teacher training, modification of school meals, and the development of school action plans targeting the curriculum, physical education, tuck shops, and playground activities.

Main outcome measures Body mass index, diet, physical activity, and psychological state.

Results Vegetable consumption by 24 hour recall was higher in children in the intervention group than the control group (weighted mean difference 0.3 portions/day, $95 \%$ confidence interval 0.2 to 0.4 ), representing a difference equivalent to $50 \%$ of baseline consumption. Fruit consumption was lower in obese children in the intervention group $(-1.0$, -1.8 to -0.2$)$ than those in the control group. The three day diary showed higher consumption of high sugar foods (0.8, 0.1 to 1.6)) among overweight children in the intervention group than the control group. Sedentary behaviour was higher in overweight children in the intervention group (0.3, 0.0 to 0.7$)$. Global self worth was higher in obese children in the intervention group ( $0.3,0.3$ to 0.6$)$. There was no difference in body mass index, other psychological measures, or dieting behaviour between the groups. Focus groups indicated higher levels of self reported behaviour change, understanding, and knowledge among children who had received the intervention. Conclusion Although it was successful in producing changes at school level, the programme had little effect on children's behaviour other than a modest increase in consumption of vegetables.
\end{abstract}

\section{Introduction}

School staff have access to large numbers of children in an environment that has the potential to support healthy behaviour and is favourable for the delivery of health promotion programmes. ${ }^{1}$ Primary schools are particularly suitable for such programmes as children in this age group are responsive to health messages and behavioural changes may be maintained into adolescence and adulthood. ${ }^{2}$
Recent reports have indicated that over $17 \%$ of 11 year old children are obese and 30\% overweight. $^{3}$ School based programmes might be able to reverse the increase in obesity. Programmes targeted at obese children and adolescents have reported positive results, particularly those aimed at primary school aged children $^{4}$ and those combining diet and exercise with parental involvement. However, most of these studies not only had inadequate methods ${ }^{5}$ but also had the problem that they targeted obese children (often volunteered by parents). Such targeting may increase stigmatisation of children at school.

An alternative strategy is to implement a health promotion programme aimed at all pupils or pupils at high risk of becoming overweight rather than at those who are already obese. Again, these initiatives have met with some success, ${ }^{5}$ although outcomes assessed in terms of change in weight or body fat are generally not as robust as those in studies targeted solely at obese pupils.

Only a few primary prevention studies of school based interventions haven been reported from the United States, ${ }^{6}$ and none in the United Kingdom. ${ }^{7}$ We designed a multicomponent health promotion programme, based on the Health Promoting Schools concept, ${ }^{8}$ aimed at reducing risk factors for obesity in primary schools. It was devised as a group randomised trial so that its effect could be appropriately assessed. We targeted children aged 8-10 because they were cognitively able to complete questionnaires and because levels of obesity start to rise around this age. ${ }^{3}$

\section{Participants and methods}

We recruited 10 primary schools in Leeds and paired them according to size, ethnicity, and level of social disadvantage (as reflected by numbers of free school meals). We randomised them to receive the intervention or to serve as the comparison school using the toss of a coin. A power calculation indicated that with five schools in each arm, the study would have $80 \%$ power to detect an underlying difference in means of a normally distributed outcome measure of $\geqslant 1.8$ standard deviations at the 5\% significance level and $65 \%$ power to detect a difference of 1.5 SD. This took into account the cluster randomisation design.

All the participating schools were state primary schools sited outside the inner city area. Sociodemographic measures suggested that the schools'
Editorial

by Atkinson

School of Health

Sciences, Leeds

Metropolitan

University, Leeds

LS1 3HE

Pinki Sahota

senior lecturer in

nutrition and dietetics

Rachael Dixey

principal lecturer in

health promotion

Leeds Community

and Mental Health

Trust, Belmont

House, Leeds

LS2 9DE

Mary C J Rudolf

consultant community

paediatrician

School of Medicine,

Leeds University,

Leeds LS2 9LT

Andrew J Hill

senior lecturer in

behavioural sciences

Leeds General

Infirmary, Leeds

LS1 3EX

Julian H Barth

consultant in chemical

pathology and

metabolic medicine

Nuffield Institute of

Health, Leeds

LS2 9PL

Janet Cade

senior lecturer in

nutritional

epidemiology

Correspondence to:

M C J Rudolf

Mary.Rudolf@

leedsth.nhs.uk

BMJ 2001;323:1-5 
Active programme promoting lifestyle in schools (APPLES)

- One year multidisciplinary, multiagency programme designed to influence diet and physical activity and not simply knowledge

- Used a population approach underpinned by the Health Promoting Schools philosophy and targeted the whole school community including parents, teachers, and catering staff

- Based on school action plans developed by the individual schools on the basis of their perceived needs

- APPLES team provided training for teachers and some resources and the project manager also provided input and support

populations generally reflected the Leeds school aged population, although there was a slight bias towards more advantaged children. The schools had 1-42\% children from ethnic minorities and 7-29\% entitled to free school meals compared with $11 \%$ and $25 \%$ respectively for Leeds children as a whole.

The intervention schools received the active programme promoting lifestyle education in schools (APPLES) (box). The programme consisted of teacher training, modifications of school meals, and the development and implementation of school action plans designed to promote healthy eating and physical activity over one academic year (September 1996-July 1997). The comparison schools continued with their usual health curriculum, without the intervention. The philosophy and details of the intervention are described in the accompanying paper, together with an evaluation of the implementation and effect of the programme. ${ }^{9}$ The study was approved by the local research ethics committee and the schools' governing bodies. Parental consent was also obtained.

\section{Main outcome measures}

We assessed the effect of the intervention on individual behaviour by collecting data on growth, diet, physical activity, and psychological state at baseline (June-July 1996) and 12 months later. These measures could not be obtained blind to the schools' intervention status.

Growth measures-Children were measured in school by the same expert auxologist. Weights were without shoes, jumpers, or sweatshirts and were recorded to within $0.1 \mathrm{~kg}$ with Seca 835 portable digital scales. Heights were measured by a standard $\operatorname{method}^{9}$ and recorded to an accuracy of $1 \mathrm{~mm}$ with a free standing Magnimeter stadiometer with rigid tripod mounting (Raven, Dunmow). We then calculated body mass index (weight in kilograms divided by the square of height in metres).

Dietary information was assessed by both 24 hour recall and three day food diaries. Recall was based on a checklist in which possible foods for each of the meals eaten during the day were listed, with an option to record foods not listed. The diary was free form. We analysed the information from both methods for frequency of consumption of foods high in fat, foods and drinks high in sugars, fruit, and vegetables.

Physical activity-The frequency of physical activity and sedentary behaviour was measured by questionnaire and was categorised by frequency of sport and physical activity during the past week (sport outside school, swimming, going for a walk, attending any club or activity where they were active, playing outside) and frequency of sedentary behaviour in past 24 hours (watching television and playing on the computer).

Psychological measures-We used three validated tools to evaluate the effect of the intervention on psychological well being: the self perception profile for children, a 36 item questionnaire with six subscales that distinguish global self worth from competence in five specific domains ${ }^{10}$; a measure of dietary restraint that has been used in children aged $8^{11}$; and the adapted body shape perception scale, which consists of a series of seven line drawings ranging from extremely thin to obese for self assessment of the individual's perception of their body size. ${ }^{12}$ The psychological data were categorised into three parts: the child's self perception, eating behaviour score $(0-12)$ reflecting the extent of dieting behaviour; and body shape preference score reflecting the degree of satisfaction with body image.

To determine the effect on children's levels of knowledge and attitudes towards healthy living, 80 focus groups involving 320 children were held at the end of year. They were conducted by two researchers blind to the schools' allocation using an interview guide with stimulus photographs of four typical meals of the day. A method of scoring was developed to measure level of knowledge and self reported changes in diet and physical activity.

\section{Analysis of data}

We applied a multilevel statistical model using STATA $^{13}$ to assess changes in body mass index, diet, physical activity, and psychological well being. This statistical model took into account the pairing and lack of independence among subjects within the school, known as the clustering effect. This was achieved by treating the analysis as a random effect meta-analysis across cluster pairs. ${ }^{14}$ In addition, we adjusted for the characteristics of the individuals (sex, age, baseline body mass index, and outcome of interest at baseline) and the intervention status of the five pairs of schools. The analysis was based on only those children measured both at baseline and at one year.

We used the Castlemead growth package ${ }^{15}$ to convert body mass index, height, and weight to standard deviation scores using the revised 1990 reference standards. We assessed the effect of the intervention by change in score after adjusting for age, sex, initial body mass index SD score, and type of school.

All outcome measures were assessed in the whole cohort, in overweight children (body mass index $>1.04$, equivalent to $>85$ th centile) and in obese children (body mass index $>1.64$, equivalent to 95 th centile on the 1990 body mass index growth charts).

\section{Results}

\section{Characteristics of sample}

In all, 636 children (314 intervention, 322 comparison) took part in the evaluation. The mean (SD) age of children in the intervention schools was $8.4(0.63)$ years, with 145 (46\%) entering school year 4 and 169 (54\%) year 5 . The mean age of the children in the comparison schools was also $8.4(0.63)$ years, with 145 (45\%) entering year 4 and $177(55 \%)$ year 5 . Table 1 shows the baseline characteristics of the sample in 
Table 1 Characteristics at baseline of children in intervention and control schools. Values are mean (SD) unless stated otherwise

\begin{tabular}{|c|c|c|c|c|c|c|}
\hline & \multicolumn{3}{|c|}{ Intervention } & \multicolumn{3}{|c|}{ Control } \\
\hline & Boys & Girls & Total & Boys & Girls & Total \\
\hline No (\%) & $161(51)$ & $153(49)$ & 314 & $189(59)$ & $133(41)$ & 322 \\
\hline Age & $8.34(0.62)$ & $8.38(0.64)$ & $8.36(0.63)$ & $8.43(0.65)$ & $8.40(0.60)$ & $8.42(0.63)$ \\
\hline No in Year 4 & 76 & 69 & 145 & 80 & 65 & 145 \\
\hline No in Year 5 & 85 & 84 & 169 & 109 & 68 & 177 \\
\hline No $(\%)>85$ th centile ${ }^{*}$ & $27(17)$ & $27(18)$ & $54(17)$ & $30(16)$ & $23(17)$ & $53(16)$ \\
\hline No (\%) >95th centile* & $8(5)$ & $12(8)$ & $20(6)$ & $22(12)$ & $13(10)$ & $35(11)$ \\
\hline Body mass index SD score & $0.07(1.05)$ & $0.17(0.96)$ & $0.12(1.01)$ & $0.06(1.17)$ & $0.02(1.17)$ & $0.04(1.17)$ \\
\hline Height SD score & $0.10(0.15)$ & $0.03(1.12)$ & $0.09(1.02)$ & $0.30(0.92)$ & $0.01(1.08)$ & $0.17(1.00)$ \\
\hline Weight SD score & $0.14(0.98)$ & $0.12(1.04)$ & $0.13(1.01)$ & $0.21(1.08)$ & $0.00(1.20)$ & $0.12(1.14)$ \\
\hline Fruit intake† & $1.9(1.7)$ & $2.2(1.7)$ & $2.0(1.7)$ & $1.9(1.6)$ & $2.1(1.6)$ & $1.9(1.6)$ \\
\hline Vegetable intake $\dagger$ & $0.5(0.7)$ & $0.7(0.7)$ & $0.6(0.7)$ & $0.6(0.7)$ & $0.5(0.7)$ & $0.5(0.7)$ \\
\hline Foods high in sugar & $7.9(5.8)$ & $6.3(4.5)$ & $7.3(4.8)$ & $8.3(5.7)$ & $7.1(4.9)$ & $7.8(5.1)$ \\
\hline Foods high in fat† & $2.0(1.2)$ & $1.7(1.0)$ & $1.8(1.1)$ & $1.7(1.2)$ & $1.9(1.1)$ & $1.7(1.1)$ \\
\hline Physical activity $\ddagger$ & $3.4(1.2)$ & $3.6(1.1)$ & $3.5(1.2)$ & $3.5(1.0)$ & $3.4(1.1)$ & $3.4(1.1)$ \\
\hline Sedentary behaviour & $1.1(0.8)$ & $1.0(0.7)$ & $1.1(0.8)$ & $1.1(0.8)$ & $0.9(0.7)$ & $1.0(0.7)$ \\
\hline
\end{tabular}

${ }^{\star}$ For body mass index.

†Number of foods in this category recorded by 24 hour recall.

†Number of activities recorded for past week.

१Number of activities recorded for past 24 hours.

Table 2 Mean (SD) scores for psychological measures at baseline for children in intervention and control schools

\begin{tabular}{lcc} 
& Intervention & Control \\
\hline Self perception (range 0-4): & & \\
\hline Scholastic competence & $2.9(0.7)$ & $2.8(0.7)$ \\
\hline Behavioural conduct & $2.9(0.7)$ & $3.0(0.7)$ \\
\hline Social acceptance & $3.0(0.7)$ & $3.0(0.7)$ \\
\hline Athletic competence & $3.0(0.7)$ & $3.0(0.7)$ \\
\hline Physical appearance & $3.1(0.7)$ & $3.0(0.7)$ \\
\hline Global self-worth & $3.2(0.6)$ & $3.1(0.7)$ \\
\hline Dieting restraint $(0-12)^{*}$ & $3.9(2.8)$ & $4.3(2.7)$ \\
\hline Boys & $3.7(3.1)$ & $3.9(2.7)$ \\
\hline Girls & $4.1(2.5)$ & $5.0(2.6)$ \\
\hline Body shape preference $\dagger$ & $0.0(1.0)$ & $0.0(1.0)$ \\
\hline Boys & $0.2(1.2)$ & $0.2(1.1)$ \\
\hline Girls & $-0.2(0.7)$ & $-0.3(0.8)$ \\
\hline
\end{tabular}

*Derived from six questions measuring dieting.

†Body shape preference is derived by subtracting the rating of preferred from currently perceived body shape. Zero indicates satisfaction, a positive value the desire to be fatter and a negative value the desire to be thinner.

terms of growth measures, diet, and physical activity and table 2 their psychological scores. No significant differences were found between the intervention and comparison pupils for any of the measures.

\section{Completion rate}

All 10 schools completed the project. The figure shows the progress of the schools through the trial. Only 21 children declined to participate in the data collection. Over the year, 42 children left and 40 new children joined. In all, $613(97 \%)$ children were measured at baseline and 595 (94\%) at the end of the intervention period; $404(63 \%)$ completed three day food and physical activity diaries at baseline and $407(64 \%)$ at the end of the study.

\section{Growth}

Table 3 shows the weighted mean difference in body mass index standard deviation score for the five pairs of schools. Overall, there was no difference in score between the intervention and control children at the end of the year. There was also no difference for the overweight (weighted mean difference - 0.07 , 95\% confidence interval -0.22 to 0.08 ) or the obese children $(-0.05,-0.22$ to 0.11$)$.
Diet

Analysis of 24 hour recall showed that the intervention children had higher vegetable intakes at the end of the study (tables 3 and 4). The weighted mean difference of $0.3(95 \%$ confidence interval 0.2 to 0.4$)$ indicates on average one third of a portion more a day. As the mean baseline was only 0.6 portions/child/day, this difference is equivalent to $50 \%$ of baseline intake. The same difference was seen for the overweight $(0.3,0.1$ to 0.5$)$ and obese children $(0.3,-0.1$ to 0.6$)$. The three day

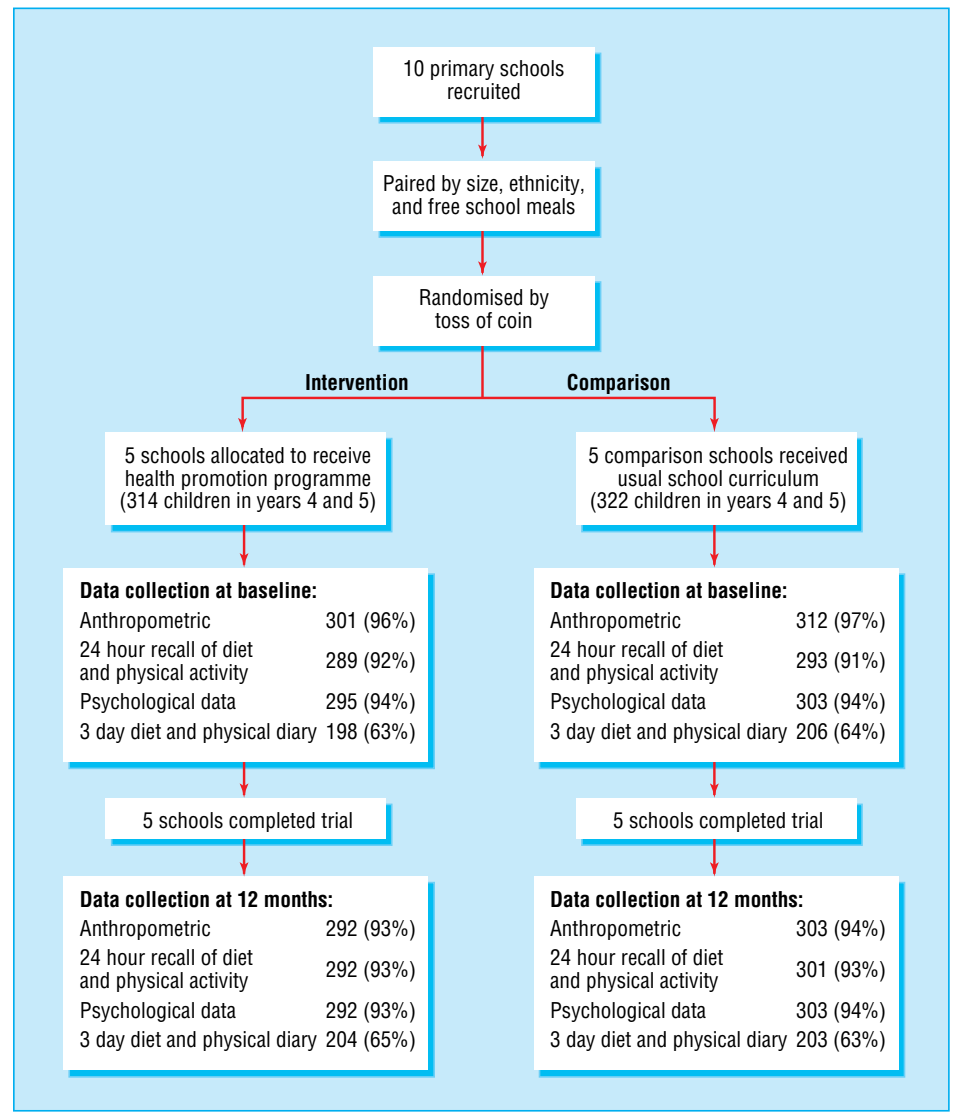

Progress of schools and pupils through trial 
Table 3 Weighted mean difference in body mass index standard deviation score and vegetable intake between the five intervention schools and their control schools

\begin{tabular}{|c|c|c|c|c|}
\hline & \multicolumn{2}{|c|}{ Body mass index SD score } & \multicolumn{2}{|c|}{ Vegetable intake } \\
\hline & $\begin{array}{l}\text { Weighted mean difference } \\
\qquad(95 \% \mathrm{Cl})\end{array}$ & $\begin{array}{l}\% \text { weight } \\
\text { of school* }\end{array}$ & $\begin{array}{c}\text { Weighted mean } \\
\text { difference }(95 \% \mathrm{CI})\end{array}$ & $\begin{array}{l}\% \text { weight } \\
\text { of school* }\end{array}$ \\
\hline 1 & $0(-0.2$ to 0.1$)$ & 25.8 & $0.2(-0.1$ to 0.4$)$ & 25.5 \\
\hline 2 & $0.1(0$ to 0.2$)$ & 18.0 & $0.4(0.2$ to 0.7$)$ & 18.2 \\
\hline 3 & $0.1(-0.1$ to 0.2$)$ & 22.5 & $0.3(0.1$ to 0.5$)$ & 23.0 \\
\hline 4 & $-0.1(-0.3$ to 0$)$ & 19.8 & $0.4(0.1$ to 0.7$)$ & 16.0 \\
\hline 5 & $-0.2(-0.3$ to 0$)$ & 13.9 & $0.1(-0.1$ to 0.4$)$ & 17.4 \\
\hline Overall & $0(-0.1$ to 0.1$)$ & & $0.3(0.2$ to 0.4$)$ & \\
\hline
\end{tabular}

*Statistical weighting

Table 4 Weighted mean difference (95\% confidence interval) in dietary and physical activity levels between intervention and control children according to weight

\begin{tabular}{lccc} 
& All children & Overweight & Obese \\
\hline 24 hr recall: & & \\
\hline Foods high in fat & $0.1(-0.2$ to 0.4$)$ & $0.4(-0.0$ to 0.9$)$ & $0.1(-0.7$ to 0.8$)$ \\
\hline Foods and drinks high in sugar & $-0.5(-1.1$ to 0.1$)$ & $0.0(-0.8$ to 0.8$)$ & $1.0(-0.5$ to 2.6$)$ \\
\hline Fruit intake & $0.0(-0.5$ to 0.5$)$ & $-0.2(-1.0$ to 0.6$)$ & $-1.0(-1.8$ to -0.2$)$ \\
\hline Vegetable intake & $0.3(0.2$ to 0.4$)$ & $0.3(0.1$ to 0.5$)$ & $0.3(-0.1$ to 0.6$)$ \\
\hline day diary: & & \\
\hline Foods high in fat & $-0.1(-0.4$ to 0.3$)$ & $0.2(-0.9$ to 1.2$)$ & $0.0(-0.8$ to 0.8$)$ \\
\hline Foods and drinks high in sugar & $0.1(-0.4$ to 0.5$)$ & $0.8(0.1$ to 1.6$)$ & $0.3(-1.8$ to 2.3$)$ \\
\hline Fruit intake & $-0.2(-0.6$ to 0.2$)$ & $-0.2(-0.7$ to 0.3$)$ & $-0.6(-1.2$ to 0.1$)$ \\
\hline Vegetable intake & $0.1(-0.1$ to 0.3$)$ & $-0.1(-0.5$ to 0.2$)$ & $-0.1(-0.9$ to 0.7$)$ \\
\hline Physical activity: & & \\
\hline Physical activity & $-0.2(-0.4$ to 0.1$)$ & $-0.2(-0.5$ to 0.2$)$ & $-0.48(-1.3$ to 0.3$)$ \\
\hline Sedentary behaviour & $0.0(-0.1$ to 0.1$)$ & $0.3(0.0$ to 0.7$)$ & $0.29(-0.1$ to 0.7$)$
\end{tabular}

A positive value for weighted mean difference indicates higher food intake or activity levels in the

intervention schools than the control schools. A value of zero indicates no difference.

diary (which had a quantitatively and qualitatively lower completion rate) did not show these differences.

Table 4 shows the full dietary assessment. Other significant differences included a lower fruit intake in obese intervention children by 24 hour recall. According to the three day diaries, there was a higher intake of foods and drinks high in sugar in overweight children in the intervention group.

Physical activity and psychological measures

We found no significant difference in physical activity or sedentary behaviour for the sample as a whole. Sedentary behaviour increased by one third in the overweight children in the intervention group compared with overweight control children. The only significant difference in psychological measures was a small increase in global self worth for obese children in the intervention schools $(0.32,0.0$ to 0.64$)$.

\section{Focus groups}

Compared with children in control schools, children in the intervention schools had higher levels of self reported behaviour change, greater understanding of the health benefits of diet and physical activity, and increased sophistication of ideas and vocabulary, willingness and confidence to share their ideas, and basic knowledge. They were more able to recollect topics learnt and activities undertaken in school linked to diet and physical activity.

\section{Discussion}

Implementation of this health promotion programme was highly successful, ${ }^{9}$ and it was therefore disappointing that the children showed minimal behavioural changes. The only clinically important positive result was a modest increase in consumption of vegetables. Vegetables are likely to be the most challenging food group to change in children, and a rise of one third of a vegetable portion per child is a huge increase in vegetables consumption across the city per day. Nevertheless, it is a small return for the effort made.

One possible reason for the apparent lack of effectiveness of the intervention could be the alarming increase in the prevalence of overweight and obesity in this entire school population. ${ }^{3}$ This rise in body mass index was seen as the children grew older as well as over time. In the face of such an epidemic, a programme with limited resources would be unlikely to have demonstrable effects in countering this increase. Clearly, the social and environmental forces at work require much larger public health counter measures.

\section{Problems of evaluating complex interventions}

Lack of evidence of effectiveness does not necessarily mean evidence of ineffectiveness. ${ }^{16}$ Inadequate sample size is often an issue in trials, and this is especially the case in studies using group randomisation. Although about 600 children participated, the unit size was only five schools in each arm, which is very small. More schools are needed to achieve a clear result. This would have been more costly and difficult to implement. Several larger health promotion trials have also had results below expectations for the same reason. ${ }^{17-22}$

The outcome measures that we used also presented difficulties. Body mass index is reliably measurable but could not be expected to change significantly over such a short time. Indeed, had body mass index fallen, we would have been concerned that we had induced inappropriate eating behaviour. The other outcome measures were less easy to measure. Although the focus groups indicated a change in self reported behaviour, we had no quantitative evidence of this. Accurate dietary assessment is difficult in any age group, but particularly in children. Few validated instruments are available, and the two methods that we used (24 hour recall and three day diary) could not assess quantities accurately. We therefore relied more on the quality of food reported. The reports of physical activity levels were even harder to quantify.

There is much debate about whether randomised controlled trials are appropriate for evaluating complex interventions, particularly in primary prevention. ${ }^{23}$ Our study, with others, raises critical issues for the development of evidence based health promotion and about appropriate measure to determine whether such interventions are effective and worthwhile.

\section{Conclusions}

Since the programme was successful in changing the ethos of the schools and the attitudes of the children, ${ }^{9}$ it is premature to conclude that it was unsuccessful in reducing risk factors for obesity. The intervention was designed for one academic year only, recognising funding limitations. The intervention might have been strengthened if the families were targeted more directly, ${ }^{24}$ while still maintaining the focus on the school community.

Other studies of this type suggest that behaviour change is possible over time. ${ }^{25}{ }^{26}$ Given the problems of evaluating behavioural intervention trials, it has been recommended that funding agencies should consider 


\section{What is already known on this topic}

Obesity is increasing among school children and demands preventive strategies

Randomised controlled trials of school based primary prevention programmes have all used a prescriptive approach

\section{What this study adds}

Behavioural changes were disappointing with this programme based on the health promoting schools philosophy, despite changes at school level

The only positive outcome was a modest increase in vegetable consumption

The discrepancy between changes achieved at the individual and school level raises issues regarding the problems inherent in such trials

supporting such trials in three phases (a development and validation phase, a small feasibility phase, and a larger multicentre trial) instead of looking for immediate positive results. ${ }^{25}$ If we view our study as a first and second phase trial, the programme was a success.

We thank the staff, pupils, and parents of Brodetsky, Cookridge, Fir Tree, Horsforth St Mary's, Moortown, Morley The Newlands, Pudsey Lowtown, Shadwell, Springbank, and the Whartons Otley primary schools for their participation, enthusiasm, and support. We also thank Jenny Walker, paediatric endocrine sister for collecting the anthropometric data, and Andy Vail for statistical advice.

Contributors: PS was the project manager and provided the main input into guiding and supporting the schools through the intervention. She collected and analysed the raw data, coordinated the programme, and drafted the article. MCJR was the principal investigator and coordinated the research team. She supervised the analysis and interpretation of the data and wrote the article jointly with PS. She will act as guarantor for the paper. RD provided the health promoting philosophy and guided the approach taken in designing the APPLES programme. She and $\mathrm{AJH}, \mathrm{JHB}$, and JC provided support in conducting the research and contributed intellectual input into the ideas behind and final format of the paper.

Funding: The research was funded by a grant from the Northern and Yorkshire Region Research and Development Unit.

Competing interests: None declared.
1 Garrow JS. Importance of obesity. BMJ 1991;303:704-6

2 Dietz WH. Childhood obesity. In: Bjorntorp P, Brodoff BN, eds. Obesity. Philadelphia: Lipincott, 1992:606-9.

3 Rudolf MCJ, Sahota P, Barth JH, Walker J. Increasing prevalence of obesity in primary school children: cohort study. BMJ 2001;322:1094-5.

4 Parcel GS, Simons-Morton BG, O'Hara NM, Baranowski T. School-based programmes to prevent or reduce obesity. In: Krasnegor NA, ed. Childhood obesity: a biobehavioral perspective. Caldwell, NJ: Telford, 1988:143-7.

5 Reniscow K. School-based obesity prevention. Ann N Y Acad Sci 1993;699:154-6.

6 Story M. School-based approaches for preventing and treating obesity. Int J Obes Metab Dis 1999;23(suppl 2):S43-51.

7 NHS Centre for Reviews and Dissemination. The prevention and treatment of obesity. Effective Health Care Bull 1997;3 (No 2).

8 Young I, Williams T, eds. The healthy school. Edinburgh: Scottish Health Education Group, World Health Organization, 1989.

9 Sahota P, Rudolf MCJ, Dixey R, Hill AJ, Barth JH, Cade J. Evaluation of implementation and effect of primary school based intervention to reduce risk factors for obesity. BMJ 2001;323:1027-9.

10 Harter S. Manual for the self-perception profile for children. Denver: University of Denver, 1985

11 Hill AJ, Pallin V. Dieting awareness and low self worth: related issues in 8 year old girls. Int J Eating Disorders 1998;24:405-13.

12 Hill AJ, Draper E, Stack J. A weight on children's minds: body shape dissatisfaction at 9 years old. Int J Eating Disorders 1994;18:383-9.

13 StataCorp. Stata statistical software; release 6.0. College Station, TX: Stata Corporation, 1999.

14 Thompson SG, Pyke SDM, Hardy RJ. The design and analysis of paired cluster randomised trials: an appreciation of meta-analysis techniques. Stat Med 1997;16:2063-79.

15 Cole TJ. Castlemead growth programmes. Welwyn Garden City: Castlemead Publications, 1993.

16 Altman D, Bland JM. Absence of evidence is not evidence of absence. BM 1995;311:485.

17 Luepker RV, Perry CL, McKinlay S, Nader PR, Parcel GS, Stone EJ, et al Outcomes of a field trial to improve children's dietary patterns and physical activity: The child and adolescent trial for cardiovascular health (CATCH). JAMA 1996;275:768-76.

18 Farquhar JW, Fortmann SP, Flora JA, Taylor CB, Haskell WL, Williams PT, et al. Effect of community-wide education on cardiovascular disease risk factors: The Stanford five-city project. JAMA 1990;264:359-65.

19 Luepker RV, Murray DM, Jacobs DR Jr, Mittelmark MB, Bracht N, Carlaw $\mathrm{R}$, et al. Community education for cardiovascular disease prevention: risk factor changes in the Minnesota heart health programme. Am J Public Health 1994;84:1383-93.

20 Carleton RA, Lasaster TM, Assaf AR, Feldman HA, McKinlay S. The Pawtucket heart health program: community changes in cardiovascular risk factors and projected disease risk. Am J Public Health 1995;85:777-85.

21 COMMITT Research Group. Community intervention trial for smoking cessation (COMMTTT): I. Cohort results from a four year community intervention. Am J Public Health 1995;85:183-92.

22 COMMITT Research Group. Community intervention trial for smoking cessation (COMMITT): II. Changes in adult cigarette smoking prevalence. Am J Public Health 1995;85:193-200.

23 Green J, Tones K. Towards a secure evidence base for health promotion. J Public Health Med 1999;21:133-9.

24 Fruhbeck G. Childhood obesity: time for action, not complacency. BMJ 2000;320:328-9.

25 CART Project Team. Developing methodologies for evaluating community-wide health promotion. Health Promotion International 1996;11(3):227-35

26 Contento IR, Balch GI, Bronner YL, Lytle LA, Maloney SK, White SL, et al. Nutrition education for school-aged children. J Nutr Educ $1995 ; 27: 298-311$

(Accepted 12 July 2001) 